\title{
Short communication: Genetic characterization of antimicrobial resistance in Acinetobacter isolates recovered from bulk tank milk
}

\author{
M. D. Tamang, M. Gurung, H. M. Nam, S. R. Kim, G. C. Jang, S. C. Jung, and S. K. Lim ${ }^{1}$ \\ Bacterial Disease Division, Animal and Plant Quarantine Agency, 175 Anyang-ro, Manan-gu, Anyang city, Gyeonggi-do, 430-757, \\ Republic of Korea
}

\begin{abstract}
A total of 176 Acinetobacter isolates, including 57 Acinetobacter baumannii originally obtained from 2,287 bulk tank milk (BTM) samples in Korea was investigated for the genetic basis of antimicrobial resistance using molecular methods. In addition, the occurrence and cassette content of integrons were examined and the genetic diversity of $A$. baumannii strains identified was evaluated. Aminoglycoside-modifying enzyme genes were detected in $15(88.2 \%)$ of the 17 aminoglycosideresistant Acinetobacter isolates tested. The most common aminoglycoside-modifying enzyme gene identified was adenylyltransferase gene $a a d B(\mathrm{n}=9)$, followed by phosphotransferase genes aphA6 $(\mathrm{n}=7)$ and aphA1 (n $=5)$. Of the 31 isolates resistant to tetracycline, tet(39) was detected in 20 of them. The genetic basis of resistance to sulfonamide was identified in $15(53.6 \%)$ of 28 trimethoprim-sulfamethoxazole-resistant isolates and 9 $(32.1 \%)$ of them carried both sul1 and sul2 genes. A $b l a_{\mathrm{ADC}-7-\text { like }}$ gene was detected in $1 \beta$-lactam-resistant $A$. baumannii. Furthermore, class 1 integron was identified in 11 Acinetobacter isolates. Two gene cassettes $d f r A 15$, conferring resistance to trimethoprim, and aadA2, conferring resistance to aminoglycosides, were identified in 8 Acinetobacter isolates. None of the isolates was positive for class 2 or class 3 integrons. Pulsed-field gel electrophoresis revealed that most of the A. baumannii strains from BTM samples were genetically diverse, indicating that the occurrence of $A$. baumannii strains in BTM was not the result of dissemination of a single clone. Elucidation of resistance mechanisms associated with the resistance phenotype and a better understanding of resistance genes may help in the development of strategies to control infections, such as mastitis, and to prevent further dissemination of antibiotic resistance genes. To the best of our knowledge, this is the first report of molecular characterization of antimicrobialresistant Acinetobacter spp. from milk.
\end{abstract}

Received August 22, 2013.

Accepted October 19, 2013

${ }^{1}$ Corresponding author: imsk0049@korea.kr
Key words: bulk tank milk, Acinetobacter, tetracycline resistance gene tet(39), class 1 integron

\section{Short Communication}

Milk is not only an important source of nutrients for humans (Sharma and Joshi, 1992) but also an ideal growth medium for bacteria (Henry and Newlander, 1997). A wide variety of pathogenic as well as commensal bacteria have been isolated from bulk tank milk (BTM), which can become contaminated with bacteria from various sources, including teat and udder surfaces, infected mammary glands, milking machines, transporting systems, contaminated water, and the dairy farm environment (Thomas and Thomas, 1973; Jayarao and Wang, 1999; Straley et al., 2006). Ironically, the use of antimicrobials in dairy herds, such as for mastitis treatment, has led to an increase in the isolation rate of antimicrobial-resistant bacteria from raw BTM, which is a matter of public health concern (Straley et al., 2006).

Acinetobacter species are strictly aerobic, gramnegative, nonfermenting bacteria that are ubiquitous in nature (Bergogne-Bérézin and Towner, 1996). Among the currently known genomic species, Acinetobacter baumannii is the most prevalent species in clinical specimens (Dijkshoorn et al., 2007). Other Acinetobacter spp., including Acinetobacter pittii (formerly Acinetobacter genomic species 3), Acinetobacter nosocomialis (formerly Acinetobacter genomic species 13TU), Acinetobacter lwoffii (genomic species 9), Acinetobacter ursingii, Acinetobacter johnsonii, and Acinetobacter parvus, have also been found to be clinically relevant (Dijkshoorn et al., 2007; Nemec et al., 2011). Acinetobacter baumannii causes a significant proportion of nosocomial infections in severely ill patients in intensive care units or immunocompromised individuals (Bergogne-Bérézin and Towner, 1996; Villegas and Hartstein, 2003; Peleg et al., 2008). The organism has emerged as an important cause of community-acquired pneumonia and other infections (Chen et al., 2001). Furthermore, clinical roles of non- $A$. baumannii species are increasingly being recognized worldwide (Karah et al., 2011). 
Acinetobacter spp. have rarely been reported from food animals or animal products for human consumption (Hamouda et al., 2011). However, infections due to $A$. baumannii have been reported in pets and horses from Switzerland in which the majority of the infections were hospital acquired and in animals with predisposing conditions. Moreover, those authors found that these $A$. baumannii strains shared the sequence types and molecular background of resistance with those described in humans (Endimiani et al., 2011). Thus, the animals or their products, or both, could serve as reservoirs of antimicrobial-resistant $A$. baumannii for humans. A better understanding of the basis of antibiotic resistance mechanisms of antimicrobial-resistant Acinetobacter associated with food animals or their product may help in the development of therapy regimens and treatment of the disease.

Although much has been reported regarding the genetic characteristics of $A$. baumannii or Acinetobacter spp. isolated from nosocomial or community-acquired infections, little is known about Acinetobacter isolates from milk. Recently, we reported the prevalence and antimicrobial susceptibility of Acinetobacter spp. from raw BTM samples from Korea (Gurung et al., 2013). Because a detailed genetic analysis of these isolates was not performed, data regarding Acinetobacter spp. from BTM are still rare. Therefore, the present study was undertaken to investigate the genetic basis of antimicrobial resistance in Acinetobacter isolates recovered from BTM samples and to determine the clonal relatedness of the A. baumannii strains identified.

A total of 176 Acinetobacter isolates, including $57 \mathrm{~A}$. baumannii strains, originally recovered from 2,287 BTM samples from various dairy farms located in 6 provinces of Korea during the period between November 2011 and April 2012 (Gurung et al., 2013) were included in this study. The collection of BTM samples and isolation, identification, and phenotypic characterization of Acinetobacter isolates were described extensively in our previous report (Gurung et al., 2013).

The presence of the following genes was determined by PCR amplification: the genes encoding aminoglycoside-modifying enzymes aacC1, aacC2, aacA4, aphA1, aphA6, aadB, and aadA1 (Clark et al., 1999; NoppeLeclercq et al., 1999; Vila et al., 1999); the genes encoding $16 \mathrm{~S}$ rRNA methylase armA, rmt $A, r m t B, r m t C$, and $r m t D$ (Doi et al., 2004; Yan et al., 2004; Wachino et al., 2006; Doi et al., 2007); tetracycline resistance genes $\operatorname{tet}(\mathrm{A}), \operatorname{tet}(\mathrm{B}), \operatorname{tet}(\mathrm{C}), \operatorname{tet}(\mathrm{H}), \operatorname{tet}(\mathrm{M})$, and $\operatorname{tet}(39)$ common in Acinetobacter (Sengeløv et al., 2003; Agers $\varnothing$ and Petersen, 2007); the genes encoding sulfonamide resistance sul1, sul2, and sul3 (Agers $\varnothing$ and Petersen, $2007)$; the genes encoding $\beta$-lactamases $b l a_{\mathrm{TEM}}, b l a_{\mathrm{SHV}}$, $b l a_{\mathrm{CTX} \text {-M }}$, and bla $a_{\mathrm{PER}-1}$ (Batchelor et al., 2005; Lee et al., 2008; Rayamajhi et al., 2008); the Acinetobacterderived cephalosporinase $b l a_{\mathrm{ADC}-7-\text { like }}$ gene encoding class C $\beta$-lactamase (Hujer et al., 2005); and the genes encoding class D $\beta$-lactamases OXA-23-like, OXA-24like, OXA-51-like, and OXA-58-like (Woodford et al., 2006).

Polymerase chain reaction amplification of class 1 (intI1), class 2 (intI2), and class 3 (intI3) integrase genes was performed using primer sets and conditions, as described previously (Machado et al., 2005). Class 1 integron cassette regions were amplified using primer pairs Att-1-F and $3^{\prime} \mathrm{CS}-\mathrm{R}$, as described previously (Agers $\varnothing$ and Petersen, 2007). To analyze the sequences of the gene cassette regions of the integrons, the purified PCR products were directly sequenced in both directions by the dideoxy-chain termination method using an automated ABI Prism 3700 analyzer (Applied Biosystems Inc., Foster City, CA). The sequences thus analyzed were compared with the sequences in GenBank using the BLAST program at the National Center for Biotechnology Information (http://www.ncbi.nlm.nih. gov/BLAST).

Pulsed-field gel electrophoresis (PFGE) was performed as previously described, with slight modification (Seifert et al., 2005). For PFGE pattern analysis, BioNumerics software (version 4.0; Applied Maths NV, Sint-Martens-Latem, Belgium), with the unweightedpair group method using average linkages (UPGMA) and the Dice setting for clustering analysis was applied to produce a dendrogram.

Aminoglycoside resistance in Acinetobacter spp. mostly involves production of aminoglycoside-modifying enzymes (AME; phosphotransferase, adenylyltransferase, and acetyltransferase) and all 3 classes of AME are widespread in Acinetobacter spp. (Hujer et al., 2006). In the current study, investigation of 17 aminoglycoside-resistant isolates for underlying resistance mechanisms revealed 6 different AME genes in various combinations in the 15 isolates. Eight (47.1\%), $4(23.5 \%)$, and $3(17.6 \%)$ isolates had 1,2 , and $3 \mathrm{AME}$ genes, respectively. The most common AME gene identified was adenylyltransferase gene $\operatorname{aadB}(\mathrm{n}=9)$, followed by phosphotransferase genes aphA6 $(\mathrm{n}=7)$ and aphA1 $(\mathrm{n}=5)$. Other genes encoding AME included the acetyltransferase genes aacC1 $(\mathrm{n}=2)$, aacC2 $(\mathrm{n}=$ $1)$, and adenylyltransferase gene $\operatorname{aadA1}(\mathrm{n}=1)$. The $16 \mathrm{~S}$ rRNA methylase genes armA, rmtA, rmtB, and $r m t C$ were not detected in any Acinetobacter isolate tested. Our results are consistent with earlier reports showing that the AME genes identified in this work are common in Acinetobacter resistant to aminoglycosides (Hujer et al., 2006). Moreover, Cho et al. (2009) reported high prevalence of armA, aadA1, aphA1, aacC1, $a a c A 4$, and $a p h A 6$ determinants among human clinical 
Acinetobacter spp. in Korea. The resistance phenotypes and genotypes were correlated in all but 2 aminoglycoside-resistant Acinetobacter isolates in the current study. These 2 isolates were negative for any type of the studied 16S rRNA methylase and AME genes and may carry other resistance mechanisms against aminoglycosides, such as impermeability of the drugs, efflux pumps, or other rare types of AME.

Of the total 31 isolates resistant to tetracycline, tet(39) was detected in $20(64.5 \%)$ of them. Other tetracycline resistance determinants tet $(\mathrm{A}), \operatorname{tet}(\mathrm{B}), \operatorname{tet}(\mathrm{C})$, tet $(\mathrm{H})$, and tet $(\mathrm{M})$ sought were not identified in any isolate. So far, $\operatorname{tet}(\mathrm{A}), \operatorname{tet}(\mathrm{B}), \operatorname{tet}(\mathrm{H}), \operatorname{tet}(\mathrm{M})$, and $\operatorname{tet}(39)$ determinants have been described for Acinetobacter spp. (Agers $\varnothing$ and Petersen, 2007; Peleg et al., 2008). However, none of the targeted determinants was found in the remaining $38.7 \%$ of the tetracycline-resistant isolates. These isolates may harbor unknown tetracycline resistance determinants or genes that were not examined in this study. The tet(39) gene was first reported among unrelated Acinetobacter strains isolated from freshwater trout farms and sewage from Denmark, and from a clinical specimen in the Netherlands (Agers $\varnothing$ and Guardabassi, 2005), followed by identification of tet(39) in $75 \%$ of 222 oxytetracycline-resistant Acinetobacter spp. isolated from integrated fish farms in Thailand (Agers $\varnothing$ and Petersen, 2007). Similarly, tet(39) genes were found in 34 of 89 single-patient tetracycline-resistant A. baumannii-Acinetobacter calcoaceticus complex isolates from a US military hospital (Akers et al., 2009). Thus, our findings and those of others suggest that the tet(39) gene is widespread among Acinetobacter strains.

Genes encoding resistance to sulfonamide, such as sul1, are highly prevalent in A. baumannii and other Acinetobacter spp. This may be attributed to strong association of the sul1 gene with class 1 integrons, which are themselves highly prevalent in Acinetobacter spp. (Poirel et al., 2011). In the current study, the genetic basis of resistance to sulfonamide was identified in 15 (53.6\%) of 28 trimethoprim-sulfamethoxazole-resistant isolates and $9(32.1 \%)$ of them carried both sul1 and sul2 genes. The sul1 gene alone and sul2 alone were found in 3 isolates each. No sul3 gene was detected. Consistent with our observation, a combination of sul1 and sul2 genes in Acinetobacter spp. have been reported from manured agricultural soils and pig slurry in the United Kingdom (Byrne-Bailey et al., 2009). Similarly, the sul2 gene was found widely distributed among clonally distinct Acinetobacter spp. isolated from both fish ponds and manure from integrated fish farms in Thailand (Agers $\varnothing$ and Petersen, 2007).

Among the 42 Acinetobacter isolates resistant to $\beta$-lactam antibiotics, Acinetobacter-derived AmpC cephalosporinase $b l a_{\mathrm{ADC}-7-\text { like }}$ gene was detected in a single A. baumannii isolate. However, 3 distinct class D OXA enzyme genes were identified, irrespective of resistance to $\beta$-lactams. Although OXA-51-like gene was identified in all A. baumannii isolates, OXA-23-like gene and OXA-24-like genes were identified only in 1 and 2 Acinetobacter spp., respectively. Acinetobacter strains are naturally resistant to $\beta$-lactams, due to intrinsic AmpC-type cephalosporinase production at a low level (Poirel et al., 2011). Although a wide range of class A extended-spectrum $\beta$-lactamases, including those of the TEM, SHV, CTX-M, and PER families, has been described, particularly among A. baumannii isolates (Gordon and Wareham, 2010), such resistant genes sought were not detected in any of the $\beta$-lactamresistant Acinetobacter in the current study. Our findings suggest that other resistance mechanisms, such as porins loss, active drug efflux, and modification of penicillin-binding proteins, among others, may be implicated for their $\beta$-lactam resistance.

Integrons, particularly class 1 integrons, have been reported in clinical isolates of Acinetobacter spp. from humans and in isolates from diverse environments all over the world (Agers $\varnothing$ and Petersen, 2007; Byrne-Bailey et al., 2009; Lin et al., 2010). Among the 176 Acinetobacter isolates tested, a class 1 integron was identified in the $11(6.25 \%)$ isolates in the present study. None of the isolates was positive for class 2 integrons (intI2) or class 3 integrons (intI3). All class 1 integron-positive isolates were resistant to trimethoprim-sulfamethoxazole and carried sul1 as a part of the integron. Two antibiotic resistance gene cassettes $d f r A 15$ and aadA2 were identified in 8 of the 11 class 1 integrase-positive isolates. The $d f r A 15$ gene cassette encodes for dihydrofolate reductase, conferring resistance to trimethoprim, and its presence as a gene cassette explained the trimethoprim resistance phenotype in $8(28.6 \%)$ of the 28 trimethoprim-sulfamethoxazole-resistant isolates. The genes coding for trimethoprim resistance $(d f r)$ have also been previously reported within integron structures in A. baumannii (Peleg et al., 2008). Similarly, the aadA2 gene encodes a variant of aminoglycoside adenylyltransferase, conferring resistance to spectinomycin and streptomycin. Importantly, the $d f r A 15-a a d A 2$ cassette array found in the current study has not been reported previously, to our knowledge. Thus, this finding indicates the important role of this gene combination in the extension and spread of resistance to trimethoprim and aminoglycosides.

Among the 176 Acinetobacter strains isolated from BTM samples from different provinces of Korea $(\mathrm{Gu}-$ rung et al., 2013), none of them were resistant to cefepime, carbapenems, fluoroquinolones, or polymixins. Resistance to aminoglycosides, tetracycline, trimethoprim-sulfamethoxazole, and $\beta$-lactams was 9.7, 17.6, 
Dice (Tol $1.0 \%-1.0 \%)(\mathrm{H}>0.0 \% \mathrm{~S}>0.0 \%)[0.0 \%-100.0 \%]$

Acinetobacter

Acinetobacter

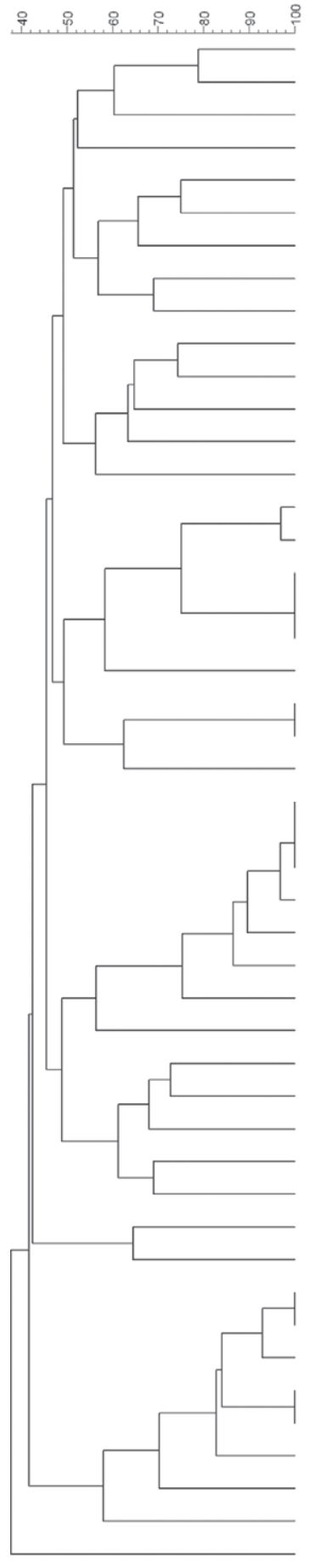

|| |||||||||| $\mid$

|| ||| ||| || |||||||

| | || | || || ||||||||||

|| || || ||| | ||||||

$\|||||||||||||$

|| | | || |||||||||

|| || | ||| |||||| |

|| || || || || ||||

| || | || || || | |||

|| | | ||| || ||||||| |

| | | |||||||||||||||

|| $\quad$ | || ||| || || ||

|| |'| |||||||||| $\mid$

|| || || ||| |||| ||| ||

| || ||||| ||| ||||

| || | |||| | ||||||||

| || | ||||| ||| |||||||

| || |||||| ||| ||||||

|| | ||\| | || \|\|\|\|

||| |||||| | || |||

|| | ||| | ||||||||

|| | ||| | |||||||| $\mid$

|| || |||||| ||| |||

|| $\||||||||| \mid$

|| || | || || ||||

|| || | || || ||||

|| || | || || |||||

|| |||||||||||| $\mid$

||| ||| | ||||| | ||||

|| || || || || ||

|| ||| ||| || |||||||

||| |||| ||||||||||

|| | | ||||||||||||

| | | || || || |||

|| $\quad$ | ||'|||| || ||| ||

-| | | || ||||||

| | | | ||||| || ||||

| ||| |||||| || ||

|| |||||| | ||||

|| | |||||| | ||||

||| | | ||| | ||||

$\||+||||||| \mid$

| | | | ||| | | |||

|| | ||||||||||

| | | || || || || ||

|| || || |||| || || |

\begin{tabular}{|c|c|c|c|c|}
\hline $11-09$ & Gyeonggi & 2011.12.19 & - & 1 \\
\hline $11-24$ & Gyeonggi & 2011.11 .18 & - & II \\
\hline $12-01$ & Chungnam & 2012.03 .09 & SXT & III \\
\hline $11-14$ & Gyeonggi & 2011.11 .18 & - & IV \\
\hline $1-04$ & Gyeonggi & 2011.12 .14 & - & V \\
\hline $11-17$ & Gyeonggi & 2011.11.18 & - & VI \\
\hline $11-01$ & Incheon & 2011.12 .06 & - & VII \\
\hline $11-33$ & Gwangwon & 2011.11.23 & - & VIII \\
\hline $11-03$ & Gyeonggi & 2011.12 .14 & - & IX \\
\hline $11-27$ & Gyeonggi & 2011.11.18 & - & $x$ \\
\hline $12-38$ & Chungbuk & 2012.03 .27 & GEN,TET & $X I$ \\
\hline $11-16$ & Gyeonggi & 2011.11 .18 & GEN & XII \\
\hline $12-39$ & Gyeonggi & 2012.03 .27 & - & XIII \\
\hline $12-04$ & Chungnam & 2012.03 .09 & SXT, GEN & XIV \\
\hline $12-40$ & Gyeonggi & 2012.03 .27 & - & $x V$ \\
\hline $12-49$ & Chungbuk & 2012.03 .27 & - & $x V$ \\
\hline $12-35$ & Chungnam & 2012.03 .27 & - & XVI \\
\hline $12-36$ & Chungbuk & 2012.03 .27 & - & $\mathrm{XVI}$ \\
\hline $12-37$ & Chungbuk & 2012.03 .27 & - & $\mathrm{XVI}$ \\
\hline $12-60$ & Chungnam & 2012.04 .03 & - & XVII \\
\hline $12-52$ & Chungnam & 2012.03 .27 & - & XVIII \\
\hline $12-53$ & Chungnam & 2012.03 .27 & - & XVIII \\
\hline $12-34$ & Chungnam & 2012.03 .27 & - & XIX \\
\hline $12-42$ & Gyeonggi & 2012.03 .27 & - & $x x$ \\
\hline $12-45$ & Chungnam & 2012.03 .27 & - & $x x$ \\
\hline $12-47$ & Gyeonggi & 2012.03 .27 & - & $x x$ \\
\hline $12-46$ & Chungnam & 2012.03 .27 & - & $x x$ \\
\hline $12-43$ & Chungnam & 2012.03 .27 & - & $x x$ \\
\hline $12-41$ & Chungbuk & 2012.03 .27 & - & $x x$ \\
\hline $12-65$ & Chungnam & 2012.04 .03 & - & $X X I$ \\
\hline $12-06$ & Chungnam & 2012.03 .09 & - & $X X I I$ \\
\hline $11-45$ & Gyeonggi & 2011.11 .23 & - & XXIII \\
\hline $11-49$ & Gyeonggi & 2011.11 .30 & - & XXIV \\
\hline $11-55$ & Gyeonggi & 2011.11 .30 & TET & $X X V$ \\
\hline $11-66$ & Gyeonggi & 2011.11 .30 & SXT, GEN,TET & XXVI \\
\hline $11-07$ & Gyeonggi & 2011.12.19 & GEN & $X X V I I$ \\
\hline $11-34$ & Gyeonggi & 2011.11 .23 & - & XXVIII \\
\hline $11-110$ & Gyeonggi & 2011.12 .07 & - & $X X I X$ \\
\hline $12-48$ & Chungbuk & 2012.03 .27 & - & $x x x$ \\
\hline $12-64$ & Gyeonggi & 2012.04 .03 & - & $x x x$ \\
\hline $12-50$ & Chungbuk & 2012.03 .27 & - & $x X X$ \\
\hline $12-44$ & Gyeonggi & 2012.03 .27 & - & $X X X I$ \\
\hline $12-59$ & Gyeonggi & 2012.04 .03 & - & $X X X I$ \\
\hline $12-66$ & Chungnam & 2012.04 .03 & - & $X X X I 1$ \\
\hline $12-51$ & Chungnam & 2012.03 .27 & - & XXXIII \\
\hline $12-14$ & Gyeongbuk & 2012.03 .20 & - & XXXIV \\
\hline $11-40$ & Gwangwon & 2011.11 .23 & - & $X X X V$ \\
\hline
\end{tabular}

Figure 1. Dendrogram showing the cluster analysis of pulsed-field gel electrophoresis (PFGE) patterns of 47 Acinetobacter baumannii strains isolated from bulk tank milk samples. The cluster analysis was performed by using the Dice coefficient and the unweighted-pair group method with arithmetic averages. Details given (in the first through seventh columns from the left) are percentage similarity, PFGE banding patterns, strain number, province, date of isolation (year.month.day), resistance phenotype, and pulsotype for each strain, respectively. 
15.9 , and $23.9 \%$, respectively. In general, the carriage of the AME gene and tet(39) gene was largely responsible for resistance to aminoglycosides and tetracycline, respectively. Similarly, the presence of sul1, sul2, or both, and the $d f r A 15$ gene cassette was mostly responsible for resistance to trimethoprim-sulfamethoxazole, whereas resistance to extended spectrum $\beta$-lactams in $1 A$. baumannii isolate was due to the $b l a_{\mathrm{ADC}-7 \text {-like }}$ gene. Because bacteria bearing resistance genes in BTM could be important reservoirs of these genes, the presence of Acinetobacter strains carrying various resistance genes in BTM is a matter of public health concern, particularly when an increasing number of people consume unpasteurized milk or products made from unpasteurized milk (Oliver et al., 2009).

Pulsed-field gel electrophoresis was performed to determine the clonal relatedness of 47 of the $57 \mathrm{~A}$. baumannii isolates. No DNA banding patterns were obtained from the $10 \mathrm{~A}$. baumannii strains due to constant autodigestion of the genomic DNA during agarose plug preparation and were, thus, excluded. Based on a similarity value of 0.85 , the 47 isolates represented 35 arbitrary (designated as I through XXXV) pulsotypes (Figure 1), including 29 singleton types and 6 different clusters consisting of 2 to 6 indistinguishable and (or) highly related isolates. Overall, a large number of $A$. baumannii strains were genetically heterogeneous, indicating that they were not derived from a single clone of A. baumannii. Unexpectedly, PFGE results also revealed that $A$. baumannii strains obtained from distantly located farms within a province but mostly from different provinces shared identical PFGE profiles. Although it is difficult to explain precisely, it can be speculated that a few independent clones of $A$. baumannii strains might have clonally disseminated or persisted among various farms, not only within a province but also between different adjoining provinces. However, such speculation should be confirmed by further study, such as by multiple-locus variable number tandem repeat (VNTR) analysis of 7 loci (MLVA-7), which has been reported to have greater discrimination power than PFGE in some instance (Hu et al., 2013).

A few limitations existed in this study. The genetic basis of resistance in some of the antimicrobial-resistant Acinetobacter strains could not be established in spite of repeated attempts. Similarly, clonal diversity between the A. baumannii isolates was assessed only by PFGE and no other genotyping method was used to confirm PFGE findings. Furthermore, we did not investigate the transferability of plasmids carrying antimicrobial resistance genes. As tet(39) is often associated with horizontally transferable plasmids (Agers $\varnothing$ and Guardabassi, 2005; Agers $\varnothing$ and Petersen, 2007), further studies are needed to determine the transferability of these plasmids because of the possibility of horizontal transfer of this gene to various bacteria in dairy farms and other ecosystems, including to humans via the food chain.

In conclusion, we determined the genetic basis for aminoglycoside, tetracycline, and sulfamethoxazole resistance in most of the A. baumannii and Acinetobacter spp. isolated from BTM samples. As the presence of antimicrobial-resistant Acinetobacter in BTM, which is one of the agents of mastitis (Malinowski et al., 2006), has obvious implications for the treatment of infected animals, the elucidation of their resistance mechanism associated with the resistance phenotype and a better understanding of resistance genes may help in the development of strategies to control infections such as mastitis and to prevent further dissemination of antibiotic resistance genes. To the best of our knowledge, this is the first report of molecular characterization of antimicrobial-resistant Acinetobacter spp. from milk.

\section{ACKNOWLEDGMENTS}

This work was supported by a grant from the Animal and Plant Quarantine Agency, Ministry of Agriculture, Food, and Rural affairs (Gyeonggi-do, Republic of Korea).

\section{REFERENCES}

Agersø, Y., and L. Guardabassi. 2005. Identification of Tet 39, a novel class of tetracycline resistance determinant in Acinetobacter spp. of environmental and clinical origin. J. Antimicrob. Chemother. 55:566-569.

Agers $\varnothing$, Y., and A. Petersen. 2007. The tetracycline resistance determinant Tet 39 and the sulphonamide resistance gene sulII are common among resistant Acinetobacter spp. isolated from integrated fish farms in Thailand. J. Antimicrob. Chemother. 59:23-27.

Akers, K. S., K. Mende, H. C. Yun, D. R. Hospenthal, M. L. Beckius, X. Yu, and C. K. Murray. 2009. Tetracycline susceptibility testing and resistance genes in isolates of Acinetobacter baumanniiAcinetobacter calcoaceticus complex from a U.S. military hospital. Antimicrob. Agents Chemother. 53:2693-2695.

Batchelor, M., K. Hopkins, E. J. Threlfall, F. A. Clifton-Hadley, A. D. Stallwood, R. H. Davies, and E. Liebana. 2005. bla $a_{\mathrm{CTX}-\mathrm{M}}$ genes in clinical Salmonella isolates recovered from humans in England and Wales from 1992 to 2003. Antimicrob. Agents Chemother. 49:1319-1322.

Bergogne-Bérézin, E., and K. J. Towner. 1996. Acinetobacter spp. nosocomial pathogens: Microbiological, clinical, and epidemiological features. Clin. Microbiol. Rev. 9:148-165.

Byrne-Bailey, K. G., W. H. Gaze, P. Kay, A. B. A. Boxall, P. M. Hawkey, and E. M. Wellington. 2009. Prevalence of sulfonamide resistance genes in bacterial isolates from manured agricultural soils and pig slurry in the United Kingdom. Antimicrob. Agents Chemother. 53:696-702.

Chen, M.-Z., P.-R. Hsueh, L.-N. Lee, C.-J. Yu, P.-C. Yang, and K.-T. Luh. 2001. Severe community-acquired pneumonia due to Acinetobacter baumannii. Chest 120:1072-1077.

Cho, Y. J., D. C. Moon, J. S. Jin, C. H. Choi, Y. C. Lee, and J. C. Lee. 2009. Genetic basis of resistance to aminoglycosides in Acinetobacter spp. and spread of armA in Acinetobacter baumannii sequence group 1 in Korean hospitals. Diagn. Microbiol. Infect. Dis. 64:185-190. 
Clark, N. C., Ø. Olsvik, J. M. Swenson, C. A. Spiegel, and F. C. Tenover. 1999. Detection of a streptomycin/spectinomycin adenylyltransferase gene (aadA) in Enterococcus faecalis. Antimicrob. Agents Chemother. 43:157-160.

Dijkshoorn, L., A. Nemec, and H. Seifert. 2007. An increasing threat in hospitals: Multidrug-resistant Acinetobacter baumannii. Nat. Rev. Microbiol. 5:939-951.

Doi, Y., D. de Oliveira Garcia, J. Adams, and D. Paterson. 2007. Coproduction of novel $16 \mathrm{~S}$ rRNA methylase RmtD and metallo- $\beta$ lactamase SPM-1 in a panresistant Pseudomonas aeruginosa isolate from Brazil. Antimicrob. Agents Chemother. 51:852-856.

Doi, Y., K. Yokoyama, K. Yamane, J. Wachino, N. Shibata, T. Yagi, K. Shibayama, H. Kato, and Y. Arakawa. 2004. Plasmid-mediated 16S rRNA methylase in Serratia marcescens conferring high-level resistance to aminoglycosides. Antimicrob. Agents Chemother. 48:491-496.

Endimiani, A., K. M. Hujer, A. M. Hujer, I. Bertschy, A. Rossano, C. Koch, V. Gerber, T. Francey, R. A. Bonomo, and V. Perreten. 2011. Acinetobacter baumannii isolates from pets and horses in Switzerland: Molecular characterization and clinical data. J. Antimicrob. Chemother. 66:2248-2254.

Gordon, N. C., and D. W. Wareham. 2010. Multidrug-resistant Acinetobacter baumannii: Mechanisms of virulence and resistance. Int. J. Antimicrob. Agents 35:219-226.

Gurung, M., H. M. Nam, M. D. Tamang, M. H. Chae, G. C. Jang, S. C. Jung, and S. K. Lim. 2013. Prevalence and antimicrobial susceptibility of Acinetobacter from raw bulk tank milk in Korea. J. Dairy Sci. 96:1997-2002.

Hamouda, A., J. Findlay, L. Al Hassan, and S. G. B. Amyes. 2011. Epidemiology of Acinetobacter baumannii of animal origin. Int. J. Antimicrob. Agents 38:314-318.

Henry, A., and I. Newlander. 1997. Milk Constituents in Chemistry and Testing of Dairy Products. Pages 269-273. 5th ed. John Wiley and Sons Inc., New York, NY.

Hu, Y., B. Li, D. Jin, Z. Cui, X. Tao, B. Zhang, and J. Zhang. 2013. Comparison of multiple-locus variable-number tandem-repeat analysis with pulsed-field gel electrophoresis typing of Acinetobacter baumannii in China. J. Clin. Microbiol. 51:1263-1268.

Hujer, K. M., N. S. Hamza, A. M. Hujer, F. Perez, M. S. Helfand, C. R. Bethel, J. M. Thomson, V. E. Anderson, M. Barlow, L. B. Rice, F. C. Tenover, and R. A. Bonomo. 2005. Identification of a new allelic variant of the Acinetobacter baumannii cephalosporinase, ADC-7 3-lactamase: Defining a unique family of class C enzymes. Antimicrob. Agents Chemother. 49:2941-2948.

Hujer, K. M., A. M. Hujer, E. A. Hulten, S. Bajaksouzian, J. M. Adams, C. J. Donskey, D. J. Ecker, C. Massire, M. W. Eshoo, R. Sampath, J. M. Thomson, P. N. Rather, D. W. Craft, J. T. Fishbain, A. J. Ewell, M. R. Jacobs, D. L. Paterson, and R. A. Bonomo. 2006. Analysis of antibiotic resistance genes in multidrug-resistant Acinetobacter sp. isolates from military and civilian patients treated at the Walter Reed Army Medical Center. Antimicrob. Agents Chemother. 50:4114-4123.

Jayarao, B. M., and L. Wang. 1999. A study on the prevalence of gramnegative bacteria in bulk tank milk. J. Dairy Sci. 82:2620-2624.

Karah, N., B. Haldorsen, K. Hegstad, G. S. Simonsen, A. Sundsfjord, and Ø. Samuelsen. 2011. Species identification and molecular characterization of Acinetobacter spp. blood culture isolates from Norway. J. Antimicrob. Chemother. 66:738-744.

Lee, H.-W., Y. M. Koh, J. Kim, J.-C. Lee, Y.-C. Lee, S.-Y. Seol, D.-T. Cho, and J. Kim. 2008. Capacity of multidrug-resistant clinical isolates of Acinetobacter baumannii to form biofilm and adhere to epithelial cell surfaces. Clin. Microbiol. Infect. 14:49-54.

Lin, Y.-C., K.-C. Hsia, Y.-C. Chen, W.-H. Sheng, S.-C. Chang, M.H. Liao, and S.-Y. Li. 2010. Genetic basis of multidrug resistance in Acinetobacter clinical isolates in Taiwan. Antimicrob. Agents Chemother. 54:2078-2084.

Machado, E., R. Cantón, F. Baquero, J. C. Galán, A. Rollán, L. Peixe, and T. M. Coque. 2005. Integron content of extended-spectrum$\beta$-lactamase-producing Escherichia coli strains over 12 years in a single hospital in Madrid, Spain. Antimicrob. Agents Chemother. 49:1823-1829.
Malinowski, E., H. Lassa, A. Kłlossowska, S. Smulski, H. Markiewicz, and M. Kaczmarowski. 2006. Etiological agents of dairy cows' mastitis in western part of Poland. Pol. J. Vet. Sci. 9:191-194.

Nemec, A., L. Krizova, M. Maixnerova, T. J. van der Reijden, P. Deschaght, V. Passet, M. Vaneechoutte, S. Brisse, and L. Dijkshoorn. 2011. Genotypic and phenotypic characterization of the Acinetobacter calcoaceticus-Acinetobacter baumannii complex with the proposal of Acinetobacter pittii sp. nov. (formerly Acinetobacter genomic species 3) and Acinetobacter nosocomialis sp. nov. (formerly Acinetobacter genomic species 13TU). Res. Microbiol. 162:393-404.

Noppe-Leclercq, I., F. Wallet, S. Haentjens, R. Courcol, and M. Simonet. 1999. PCR detection of aminoglycoside resistance genes: A rapid molecular typing method for Acinetobacter baumannii. Res. Microbiol. 150:317-322.

Oliver, S. P., K. J. Boor, S. C. Murphy, and S. E. Murinda. 2009. Food safety hazards associated with consumption of raw milk. Foodborne Pathog. Dis. 6:793-806.

Peleg, A. Y., H. Seifert, and D. L. Paterson. 2008. Acinetobacter baumannii: Emergence of a successful pathogen. Clin. Microbiol. Rev. $21: 538-582$.

Poirel, L., R. A. Bonnin, and P. Nordmann. 2011. Genetic basis of antibiotic resistance in pathogenic Acinetobacter species. IUBMB Life 63:1061-1067.

Rayamajhi, N., S. G. Kang, D. Y. Lee, M. L. Kang, S. I. Lee, K. Y. Park, H. S. Lee, and H. S. Yoo. 2008. Characterization of TEM-, SHV- and AmpC-type $\beta$-lactamases from cephalosporin-resistant Enterobacteriaceae isolated from swine. Int. J. Food Microbiol. 124:183-187.

Seifert, H., L. Dolzani, R. Bressan, T. van der Reijden, B. van Strijen, D. Stefanik, H. Heersma, and L. Dijkshoorn. 2005. Standardization and interlaboratory reproducibility assessment of pulsed-field gel electrophoresis-generated fingerprints of Acinetobacter baumannii. J. Clin. Microbiol. 43:4328-4335.

Sengel $\varnothing v$, G., Y. Agers $\varnothing$, B. Halling-Sørensen, S. B. Baloda, J. S. Andersen, and L. B. Jensen. 2003. Bacterial antibiotic resistance levels in Danish farmland as a result of treatment with pig manure slurry. Environ. Int. 28:587-595.

Sharma, D. K., and D. V. Joshi. 1992. Bacteriological quality of milk and milk product with special reference to Salmonella and its public health significance. J. Food Sci. Technol. 29:105-107.

Straley, B. A., S. C. Donaldson, N. V. Hedge, A. A. Sawant, V. Srinivasan, S. P. Oliver, and B. M. Jayarao. 2006. Public health significance of antimicrobial-resistant gram-negative bacteria in raw bulk tank milk. Foodborne Pathog. Dis. 3:222-233.

Thomas, S. B., and B. F. Thomas. 1973. Psychrotrophic bacteria in refrigerated bulk-collected milk. Part I. Dairy Ind. 38:11-15.

Vila, J., J. Ruiz, M. Navia, B. Becerril, I. Garcia, S. Perea, I. LopezHernandez, I. Alamo, F. Ballester, A. M. Planes, J. MartinezBeltran, and T. J. de Anta. 1999. Spread of amikacin resistance in Acinetobacter baumannii strains isolated in Spain due to an epidemic strain. J. Clin. Microbiol. 37:758-761.

Villegas, M. V., and A. I. Hartstein. 2003. Acinetobacter outbreaks, 1977-2000. Infect. Control Hosp. Epidemiol. 24:284-295.

Wachino, J., K. Yamane, K. Shibayama, H. Kurokawa, N. Shibata, S. Suzuki, Y. Doi, N. Kimura, Y. Ike, and Y. Arakawa. 2006. Novel plasmid-mediated 16S rRNA methylase, RmtC, found in a Proteus mirabilis isolate demonstrating extraordinary high-level resistance against various aminoglycosides. Antimicrob. Agents Chemother. 50:178-184.

Woodford, N., M. J. Ellington, J. M. Coelho, J. F. Turton, M. E. Ward, S. Brown, S. G. Amyes, and D. M. Livermore. 2006. Multiplex PCR for genes encoding prevalent OXA carbapenemases in Acinetobacter spp. Int. J. Antimicrob. Agents 27:351-353.

Yan, J.-J., J.-J. Wu, W.-C. Ko, S.-H. Tsai, C.-L. Chuang, H.-M. Wu, Y.-J. Lu, and J.-D. Li. 2004. Plasmid-mediated 16S rRNA methylases conferring high-level aminoglycoside resistance in Escherichia coli and Klebsiella pneumoniae isolates from Taiwanese hospitals. J. Antimicrob. Chemother. 54:1007-1012. 